TU4B-(2)-4

\title{
EXTREMELY BROADBAND SUPERLUMINESCENT DIODES/SEMICONDUCTOR OPTICAL AMPLIFIERS IN OPTICAL COMMUNICATION BAND
}

\author{
${ }^{a}$ Chia-Wei Tsai; ${ }^{b}$ Gagik Sh. Shmavonyan, ${ }^{b}$ Yi-Shin Su, and ${ }^{b, c}$ Ching-Fuh Lin, \\ ${ }^{a}$ with Department of Physics \\ ${ }^{b}$ with Graduate Institute of Electron-Optical Engineering \\ ${ }^{c}$ with Department of Electrical Engineering and \\ Graduate Institute of Electronics Engineering \\ National Taiwan University, Taipei, Taiwan
}

Phone:886-2-23635251 ext 339, Fax: 886-2-23677467, Email:cflin@cc.ee.ntu.edu.tw

Abstract -- Superluminescent diodes with broad emission bandwidth characteristics and the mechanism of carrier distribution in the active layer are explored. Using InP substrate with five $6 \mathrm{~nm}$ InGaAsP quantum wells and two $15 \mathrm{~nm}$ InGaAs quantum wells, we get a very broad emission spectrum. The spectral width is nearly $400 \mathrm{~nm}$, almost covering the range from $1250 \mathrm{~nm}$ to $1650 \mathrm{~nm}$.

\section{INTRODUCTION}

Superluminescent diodes (SLDs) are good candidates of light sources for optical fiber communication. However, to cover the entire usable bandwidth of an optical fiber, many conventional SLDs having different spectral ranges are required. Therefore, if the bandwidth of SLDs could be broadened, they will be even more attractive.

In this paper, we repot the design of multiple quantum wells (MQW) with different types that can give the superluminescent diodes extremely broadband spectral width. The spectral width is nearly $400 \mathrm{~nm}$, almost covering from $1250 \mathrm{~nm}$ to $1650 \mathrm{~nm}$.

\section{BROADBAND CHARACTERISTIC OF THE SLD}

This sample has two $1.6 \mu \mathrm{m}$ quantum wells located at $\mathrm{n}$-side and five $1.3 \mu \mathrm{m}$ quantum wells located at p-side. Fig. 1 shows the emission spectrum of bending waveguide with $300 \mu \mathrm{m}$ length SLD at different injection current and Fig. 2 show the shows the full width at half maximum vs. injection current of this broadband SLD.

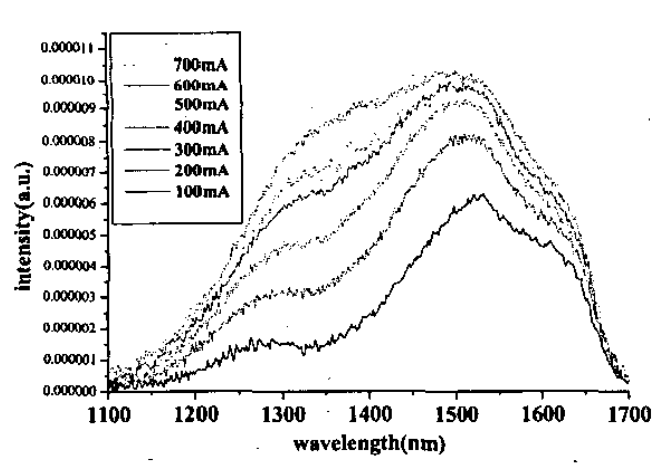

Fig. 1 Emission spectrum of bending waveguide with $300 \mu \mathrm{m}$ length SLD at different injection currents.

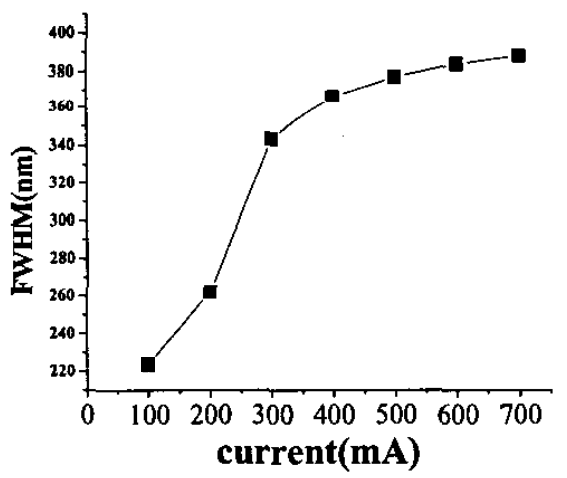

Fig. 2 Full width at half maximum (FWHM) vs. Injection current.

The broadband effect is due to carrier distribution more evenly. In the injection current about $700 \mathrm{~mA}$, the width of the spectrum is up to $388 \mathrm{~nm}$.

\section{COCLUSION}

We have demonstrated extremely broadband SLDs using two properly designed $15 \mathrm{~nm} \mathrm{In}_{0.53} \mathrm{Ga}_{0.47} \mathrm{As}$ QWs and five $6 \mathrm{~nm} \mathrm{In}_{0.67} \mathrm{Ga}_{0.33} \mathrm{As}{ }_{0.72} \mathrm{P}_{0.28}$ QWs. A spectral width covering a range from $1.25 \mu \mathrm{m}$ to $1.65 \mu \mathrm{m}$ has been achieved. The spectral width could be near $400 \mathrm{~nm}$. 